\title{
A importância da escola no processo de afirmação da identidade linguística Kiriri
}

\author{
VINESSA COLLHO MONASS \\ UNIVERSIDADE FEDERAL DA BAHIA (UFBA), SALVADOR/BA, BRASIL \\ HTTPS://ORCID.ORG/0000-0003-I805-2469
}

Os Kiriri são uma etnia indígena, situada no contexto dos povos indígenas do Nordeste. Localizados no Norte da Bahia, no município de Banzaê, ocupam um território octogonal, que teve seu decreto de homologação dos 12.320 hectares em 1995. Nele vivem aproximadamente 4 mil indígenas distribuídos em 13 aldeias.

Com base em minha pesquisa de natureza etnográfica ${ }^{1}$ sobre o processo linguístico dos Kiriri (Moraes, 2020), neste artigo, pretendo discutir a relação entre língua e identidade a partir da escola. Destaco que embora não saibam como falar sua língua cotidianamente, os Kiriri buscam efetivar um processo de "revitalização linguística", entendendo esse conceito a partir da perspectiva de Bruna Franchetto (2020:2), a qual afirma que "revitalização linguística consiste na pesquisa e desenvolvimento de metodologias de manutenção e propagação do uso de línguas ameaçadas [...] ou extintas”. A partir disso, pretendo compreender as dificuldades desse processo no âmbito da escola, bem como os desafios colocados para promover a disciplina de Língua Indígena.

Na primeira seção do artigo, apresento elementos da história desse grupo, focando em questões linguísticas e educacionais, a partir dos textos de Leite (1945), Dantas, Sampaio e Carvalho (1992), Pompa (2001) e Coelho (1999). Em seguida, discuto o processo de retomada territorial desse grupo, pois é nele que a escola indígena e a língua Kiriri assumem maior relevância. Para isso, a partir do livro de Bandeira (1972) farei uma breve descrição de como estavam socialmente antes da retomada; tendo consideração os trabalhos de Nascimento (1994) e de Brasileiro (1996) mostrarei como eles se reorga-

1 Tendo em mente a perspectiva de Ingold (2015) sobre o trabalho antropológico, passei três meses em campo em 2019, ficando em casas de diferentes lideranças. Nesse período conversei e convivi com professores, lideranças e funcionários das escolas Kiriri e frequentei, em diferentes momentos, as três principais escolas que irei descrever. Também assisti a algumas aulas de Língua Indígena e Cultura e Identidade. Além disso, estive presente em algumas reuniões escolares, em rituais, nas atividades didáticas no "dia do índio" e acompanhei a luta dos Kiriri no evento Acampamento dos Povos Indígena da Bahia. 
nizaram. Correlacionarei isso com as noções de identidade formuladas por Gimenéz (2007) e Reesink (1983) e ao conceito de etnogênese de Bartolomé (2006).

Na terceira seção do texto, detenho-me sobre o que é educação diferenciada e como a observamos nas escolas Kiriri. Sob a ótica de Tassinari (2000), analiso a escola como um espaço de fronteira. $\mathrm{Na}$ sequência, detalho o processo linguístico através das disciplinas específicas, mostrando como as disputas intraétnicas repercutem na disciplina de Língua Indígena. Por fim, sintetizo os principais elementos do texto e a relevância da reflexão proposta nesse artigo.

\section{Um pouco da história étnica e linguística do povo Kiriri}

Nos séculos XVI e XVII os Kiriri viviam em aldeamentos missionários dos jesuítas. Nesse período, como nos mostra Pompa (2001), a Companhia de Jesus ${ }^{2}$ enviou para diversos lugares do mundo padres missionários para que pudessem ampliar o número de fiéis ao cristianismo, pois acreditava-se que grupos não europeus eram culturalmente inferiores e era necessário "elevar" sua cultura, fazendo com que incorporassem hábitos e crenças europeias. Compreendia-se que a única religião verdadeira e correta era o cristianismo e todas as outras eram formas errôneas de evocar um certo tipo de espiritualidade que não conduziria o ser humano ao "reino de Deus". Além disso, esse processo colaborava para a pacificação dos povos, facilitando as entradas no Sertão e a expansão econômica. Assim, os missionários da Companhia de Jesus cumpriam uma dupla função: catequizando outros povos e expandindo o cristianismo, além de auxiliar a promover o processo de colonização.

De acordo com Dantas, Sampaio e Carvalho (1992) existiam Kiriri nos aldeamentos missionários conhecidos como Saco dos Morcegos, Juru (atualmente a cidade de Tomar do Geru/SE), Natuba (atual Nova Soure/BA) e Canabrava (hoje Ribeira do Pombal/BA). O que perdurou por mais tempo foi o de Saco dos Morcegos, onde localiza-se o atual território indígena Kiriri. Muitas etnias encontravam-se em aldeamentos missionários, pois fora destes poderiam correr o risco de morrer, sendo perseguido pelos colonos. Apesar da vida nos aldeamentos ser uma alternativa para sua sobrevivência, eles eram submetidos a um conjunto de violências e constrangimentos que discriminava seu modo de ser e promovia a catequese $(\text { Leite, } 1945)^{3}$.

A comunicação dos jesuítas com os indígenas tornou-se fundamental para implementar o projeto missionário. Assim, os padres foram estudando e aprendendo as línguas nativas e algumas obras jesuíticas sobre línguas indígenas foram escritas de modo a instrumentalizar os missionários, viabilizando a expansão da catequese e a compreensão da confissão dos indígenas. Como não era possível fazer obras sobre todas as línguas, as que eram elaboradas diminuíam as diferenças dialetais, descrevendo

2 A Companhia de Jesus foi fundada por Santo Inácio de Loyola em plena Contra Reforma, no ano de 1534. Ele e um grupo de estudantes da Universidade de Paris fizeram votos de obediência à doutrina da Igreja Católica. Foram reconhecidos pela bula papal em 1540. Procuravam combater o protestantismo, pregando o cristianismo e uma rígida obediência a essa doutrina. Essa instituição tinha como objetivo catequisar povos e nações inteiras, chegando ao Brasil com esse propósito por volta de 1549.

3 Catequizados, os indígenas não podiam praticar sua religiosidade. Eram constrangidos a aprender o português e trabalhavam para promover o aldeamento, construindo obras como igrejas e colégios, além de plantar e colher para todos que viviam nesse espaço (Leite, 1945). 
uma língua que pudesse ser comunicada com o máximo de sujeitos e de etnias de uma mesma região, já que os aldeamentos missionários eram espaços multilíngues e multiétnicos. Leite (1945) nos mostra que duas das principais obras foram produzidas pelo padre Vicencio Mamiani: Catecismo da Doutrina Christãa na Lingua Brasilica da Nação Kiriri, em 1698 e a Arte de Grammatica da Lingua Brasilica, em 1699, ambas baseadas nos aldeamentos em que Mamiani esteve no sertão.

Com o fim dos aldeamentos missionários, iniciou-se em 1755 o Diretório dos Índios ${ }^{4}$. De acordo com Coelho (1999), o Diretório tinha como principal objetivo integrar os povos indígenas à sociedade nacional, civilizando-os e impondo um modelo educacional assimilacionista, tornando a escola um meio de tornar os indígenas trabalhadores brasileiros. Nesse período, foi proibido o uso das línguas indígenas no Brasil. Mesmo assim, em 1798, com o fim do Diretório dos Índios, ainda existiam falantes de diversas línguas indígenas.

É importante notarmos que existia, tanto entre os jesuítas quanto no Diretório dos Índios, a ideia de que os povos originários eram inferiores, primitivos e selvagens, sendo um dever torná-los civilizados. Nos aldeamentos, os Kiriri deviam ser transformados em cristãos; no Diretório dos Índios, trabalhadores brasileiros. Ambas as perspectivas coloniais estavam voltadas a fazer os povos indígenas instrumentos para fins políticos de determinadas instituições. Porém, existiram processos de resistência e, por isso, tais projetos civilizadores tiveram problemas em sua implementação de modo que muitos indígenas confrontaram os colonizadores mediante estratégias que lhes possibilitassem sua sobrevivência e práticas tradicionais (Coelho, 1999; Leite, 1945; Pompa, 2001)

Com relação à língua, como já mencionado, os jesuítas usavam muito os idiomas indígenas como modo de promover a colonização. Também ensinaram o português para esses povos, no intuito de fazê-los se comunicar em uma língua mais "civilizada”, pois era comum classificarem suas línguas como feias e selvagens. No Diretório dos Índios, radicalizaram-se os esforços para integrar as etnias à sociedade nacional, tendo como consequência a busca por eliminar por completo o uso das línguas indígenas. Afinal, para que o projeto de integração fosse cumprido com sucesso, era necessário forçar os índios a se comunicarem com os não indígenas através do português (Dantas et al, 1992).

No século seguinte, ao fim do Diretório dos Índios, segundo os próprios Kiriri, os últimos falantes e pajés morreram na Guerra de Canudos 5 , quando os seus antepassados seguiram Antônio Conselheiro em busca de "montanhas de cuscuz" e "rios de leite". Não fica claro na bibliografia disponível sobre esse assunto, nem nas narrativas dos Kiriri, se todos os falantes foram mesmo para Canudos. Dentre os que ficaram será que ninguém sabia falar sua língua? Argumento, assim, não ser possível elucidar quando ou como essa língua deixou de ser falada amplamente.

4 Diretório dos Índios foi uma lei que propunha a normatização e a regulamentação de diversas práticas coloniais, estabelecendo critérios educacionais, territoriais, administração da força de trabalho e relações entre indígenas e colonos. Ao mesmo tempo em que regulava a liberdade das populações indígenas e institucionalizava seu trabalho forçado. Em função disso, várias unidades coloniais foram criadas a partir das antigas aldeias missionárias, com objetivo de levar as populações indígenas a realizar a transição para a vida civil, produzindo gêneros voltados ao comércio.

5 De acordo com Vander Velden (2003), os Kiriri seguiram Antônio Conselheiro para a Guerra de Canudos, pois este se assemelhava com os pajés, pois expressava um carisma político e se expressava também enquanto liderança religiosa. Além disso, em Canudos viam a possibilidade de sair de uma condição de miséria e galgar uma vida melhor.

6 Nas narrativas dos Kiriri eles utilizam essas expressões para se referirem às expectativas dos seus antepassados com relação ao que encontrariam em Canudos. 
Bandeira (1972), que fez pesquisa entre os kiriri na década de 1960, mostra que ninguém sabia "cortar a língua", termo nativo para se referir às pessoas que se comunicavam no seu idioma; apesar disso, ela registrou um conjunto de palavras que alguns Kiriri conheciam. Assim, demostrou a relevância desse conhecimento, ainda que estivesse, em sua maior parte perdido. Em sua dissertação, Bandeira narra que os Kiriri diziam que sua língua é fundamental para entender melhor os seres invisíveis que viviam naquela região, porém eles tinham perdido essa habilidade.

Percebamos aqui alguns dos efeitos do projeto político colonial que incidiu sobre essa etnia. Esse processo teve como uma das principais consequências o fato deles terem deixado de falar a própria língua, o que trouxe problemas na relação com seres não humanos que vivem na região.

\section{(Re)Construção identitária e a retomada territorial}

Ao longo do século XX, os Kiriri foram discriminados e inferiorizados constantemente. Compunham o segmento social mais pobre na região em que viviam, próximo onde hoje fica a cidade de Banzaê; devido à questão étnica e à situação econômica, constantemente se submetiam a humilhações para obter trabalho (Bandeira, 1972), sendo estigmatizados pelos não indígenas da região como alcoólicos, desonestos, ladrões, imorais e sujos. De acordo com Reesink (1983), os Kiriri estavam de tal modo integrados à sociedade regional que frequentemente não eram mais vistos como índios, pois, no imaginário nacional, só seriam indígenas aqueles que vivessem de maneira claramente diferente das pessoas que moravam naquela região ${ }^{7}$.

Sujeitos a discriminação e sem direitos, os Kiriri precisaram rearticular sua identidade para que fossem reconhecidos como indígenas ${ }^{8}$ e, assim, identificados como detentores do direito ao território. Cabe lembrar que o território que eles reivindicavam foi concedido originalmente em 1700 pelo rei de Portugal por meio de um Alvará Régio, o qual decretou que todos os aldeamentos que tivessem mais de cem casais indígenas receberiam um território com 12.320 hectares. Como o aldeamento de Saco dos Morcegos tinha essa dimensão, esse território se tornou um direito dos índios daquela região. Depois do Diretório dos Índios o grupo perdeu esse direito. Diante das condições que viviam na década de 1970, passaram a reivindicar a retomada do território, o que só poderia ser garantido na medida em que eles demarcassem sua identidade explicitamente.

Os Kiriri começaram então a adotar uma série de práticas que evidenciavam sua diferença frente aos segmentos sociais com os quais tinham contato para, assim, afirmar sua condição etnicamente diversa. Assim, reorganizaram a política local intraétnica, passaram a usar tanga de craoá e deixaram de fazer rituais que se assemelhavam a práticas afro-brasileiras. Como principal consequência disso,

\footnotetext{
7 Ou seja: despidos, vivendo nas matas, caçando, além de ter um fenótipo com traços marcantes das populações indígenas (Reesink, 1983).

8 Para Gimenéz (2007), a identidade tem dois aspectos centrais. O primeiro é o caráter individual, articulado a partir características próprias do indivíduo, do estilo de vida, pelas suas relações afetivas, pelas práticas individuais, sua biografia pessoal e a forma que se vê. O segundo é o caráter social, os grupos possuem identidade de oposição, se definindo a partir das suas especificidades, negando outros grupos e afirmando a si mesmo, construindo uma identidade própria.
} 
aprenderam o toré com os indígenas da etnia Tuxá. Nascimento (1994:18) sintetiza o que ocorre no toré que os Kiriri passaram a realizar:

Providências devem ser tomadas em relação à preparação do terreiro, ao ar livre, tais como a defumação. Nela um entendido, quase sempre um conselheiro, cargo político inferior apenas ao de cacique, com uma cabaça contendo ora a bebida jurema, ora o vinho de milho ou buraiê, ora o zuru (cachaça comum), sai aspergindo o líquido sobre o chão, enquanto que às suas costas, formando uma fila, seguem dois outros entendidos, homem ou mulher, um segurando uma lamparina (um fifó de querosene), outro fumando de um paú (cachimbo) e baforando ao longo de todo o trajeto, que percorre toda a área externa e interna do terreiro. Espera-se com isso, atrair os encantos e afastar os coisa rúim, espirito de morto, ou espírito branco, categoria que envolve espíritos tanto de falecidos brancos como negros. Visto de cima, o conjunto busca, em fila indiana, performar um círculo, homens a frente, girando no sentido antihorário, de forma que os primeiros, puxados pelo pajé, logo alcancem os últimos, necessariamente mais lentos, ultrapassando-os ora por dentro do círculo, ora por fora, de modo a formar uma espiral que se contrai ao máximo, quando uma inversão súbita de sentido, por parte daquele que puxa os demais, desfaz completamente a espiral, repetindo-se indefinidamente essa coreografia, que somente se altera no momento em que chegam os encantos. Juntamente com o canto e o som produzido pela maracá, há também uma pisada característica, um passo simples, o "jeito" Kiriri de pisar, através do qual costumam se distinguir de outros índios que também dançam o Toré e dos civilizados. Esse movimento em espiral é sempre paralisado quando se substitui uma linha - i.é., canto - por outra, servindo para que se tome um pouco de fôlego, permanecendo o círculo aberto - essa é a hora em que as pessoas entram e saem da formação, já que não é obrigatório que todos dancem todas as linhas. $\mathrm{O}$ ritmo tem sua frequência acelerada à medida em que se aproxima o climax, quando os encantos baixam ou enramam, dando-se aí um grande intervalo para a consulta aos encantados e a ingestão das bebidas rituais: o vinho da jurema e o buraiê." (grifos no original)

Ainda de acordo com Nascimento, esse ritual é um marcador identitário que, ao ser introduzido nessas comunidades, transforma não só a cultura, mas a noção de distinção cultural que existia com relação à sociedade não indígena. Com a prática do toré, os kiriri puderam demonstrar sua indianidade ritualisticamente, enfatizando sua diferença étnica, o que reconstrói não apenas a sua cultura, mas a sua diferença com relação à sociedade regional, negando-a. Isso era muito importante: Arruti (1995:82) nos mostra, por exemplo, que os funcionários da Funai, ao chegarem nas aldeias, pediam para que o grupo dançasse "e, dependendo da performance, em seu relatório [...] tece[m] considerações acerca da autenticidade étnica do grupo, as quais, por sua vez, serão levadas em conta ao longo do processo de oficialização do grupo". Para além disso, o toré também era importante porque reafirmava a identidade através de uma experiência religiosa, conectada com a identificação do que é ser índio. Ao incorporar o toré em sua cultura, os Kiriri estavam, portanto, se reinventando, tanto para obter seus direitos, quanto para se fortalecer internamente através da religião.

Assim como o toré, a língua emergiu como expressão identitária relevante. Durante o ritual, algumas mulheres - chamadas mestras - incorporam os encantados (entidades sagradas, que são seus antepassados) e, em um dado momento, depois da sua incorporação, vão para a "ciência do índio" ou ca- 
marinha. Nesse evento, elas, ou melhor, o encantado conversa com os indígenas, dando-lhes conselhos ou passando "remédios do mato". Há um momento em que elas falam uma língua que não é português, a qual é identificada como sendo a língua dos antigos. Por conta disso, sonham com o dia em que os encantados não precisem mais falar em português. A língua começa a expressar um importante marcador diacrítico do que é ser Kiriri, pois reafirma sua identidade, intimamente ligada à busca por aspectos relevantes, que faziam parte da vida dos seus antepassados. Isso expressa a reivindicação de uma identidade Kiriri, valorizando a história desse povo e o modo de ser dos ancestrais (Nascimento, 1994).

A partir daí, podemos perceber a demanda pela construção de uma identidade linguística própria. Isso fica explícito no relato de algumas lideranças que destacaram situações de discriminação, como quando foram para congressos nacionais de povos indígenas e pessoas de etnias do Norte disseram que os Kiriri não eram índios, porque não tinham uma língua específica ${ }^{9}$. Acusação semelhante também foi produzida por não indígenas da região onde habitam os Kiriri. Além disso, conversando com Laecio, professor de história do Colégio Estadual Indígena Florentino Domingues de Andrade, ele me contou que queria muito que, em sua etnia, as pessoas falassem seu idioma cotidianamente; não sendo praticada, ele sentia "falta" de uma identidade.

Houve, portanto, um processo de etnogênese do povo Kiriri. De acordo com Bartolomé (2006), essa categoria é usada para falar do processo de surgimento de novas etnias; para ele, apesar de assumirem uma nova identidade, não são, de fato, novas etnias de fato, pois elas se atualizam frente a novas demandas. A etnogênese é fruto de uma reorganização política que rearticula e transforma diversos elementos, sobretudo no que diz respeito a características identitárias e estratégias para obtenção de direitos frente ao Estado. A partir disso, emergem etnias enquanto sujeitos coletivos com uma identidade própria que se "mobilizam em conjunto em prol de objetivos compartilhados" (Bartolomé, 2006:54).

Isso é ainda mais expressivo no seu processo de afirmação de uma identidade linguística, na qual a língua tanto demarca a identidade de modo político, quanto é um meio de comunicação com os encantados. Negar sua condição linguística era uma ofensa direta à própria identidade; o conhecimento da língua Kiriri, por sua vez, reforçava o laço intraétnico e ampliava a comunicação com os encantados.

\section{Escolas diferenciadas}

É nesse contexto que surgiram as escolas diferenciadas dos Kiriri, as quais são a extensão desse processo de valorização cultural e resultado das suas lutas pelo território. De acordo com Côrtes (1996), desde a década de 1980 os indígenas se preocupam com uma educação escolar para o seu povo que inclua não apenas componentes do currículo básico de toda escola brasileira, mas principalmente conteúdos referentes à própria cultura e voltados a sua valorização.

As escolas na época da retomada eram muito importantes, porque através delas os kiriri se alfabetizavam e aprendiam a ler importantes documentos, bem como aprendiam a contar, podendo calcular o que ganhavam com a roça comunitária bem como o pagamento das viagens das lideranças. Tais instituições sempre estiveram associadas, portanto, a necessidades políticas. A maioria dos estabelecimen-

9 Por razões éticas, não cabe expor essa situação de maneira detalhada. 
tos de ensino já existia no seu território e eram dos não indígenas; na medida em que foram retomando suas terras, tais colégios passaram a ser dos Kiriri. Em 1995, com a homologação do território, todas as escolas dessa região tornaram-se indígenas. Embora não tenha sido possível fazer um mapeamento detalhado, sabemos através de Côrtes (1996) que em 1995 existiam 11 escolas, atendendo da pré-escola à quarta série do Ensino Fundamental.

Em minha última ida à campo, em 2019, havia três principais colégios: o Colégio Estadual Indígena Florentino Domingues de Andrade, o qual antes da estadualização chamava-se Escola Municipal Marechal Rondon; o Colégio Estadual Indígena José Zacarias, antiga Escola Municipal Professora Francisca Alice Costa; e o Colégio Estadual Indígena Kiriri Índio Feliz, que antes da estadualização tinha praticamente o mesmo nome, Escola Municipal Índio Feliz ${ }^{10}$. Cada um deles administra três escolas menores, que funcionam em outras aldeias, cada qual com duas ou três salas de maneira multisseriada ${ }^{11}$ até o Ensino Fundamental I. Nos colégios existe uma média de 240 a 300 discentes e aproximadamente 30 docentes, enquanto nas escolas menores a média é de 3 professores e entre 20 e 50 estudantes ${ }^{12}$.

Meus interlocutores não souberam informar quando surgiram tais instituições. Na década de 1990, as escolas kiriri estavam ligadas ao Município de Banzaê, e eram entendidas pelo Ministério da Educação (MEC), a partir do termo educação diferenciada (Moraes, 2018, 2020), como consta no Parecer $n^{\circ} 14 / 99$ :

As escolas indígenas são diferentes das escolas não-indígenas porque possui características de ensino próprias. Essas são grandes diferenças. Os regimentos escolares também diferem em vários pontos, como: calendário escolar, carga horária, conteúdos, metodologia de ensino, etc. É diferente porque trabalha respeitando as maneiras tradicionais dos velhos passarem os conhecimentos para os jovens. É diferente porque o professor é o principal autor de seus próprios materiais didáticos usados na escola e usa tanto o conhecimento na escrita quanto o conhecimento oral. A aproximação com a escola não-indígena é pelo caráter de ensino que fazem em busca dos seus conhecimentos sociais e da cidadania. (Brasil, 1999: 1)

Isso está em consonância com o decreto no 26 de 1991:

Art. $1^{\circ}$. Fica atribuída ao Ministério da Educação a competência para coordenar as ações referentes à educação indígena, em todos os níveis e modalidades de ensino, ouvida a FUNAI.

Art. $2^{\circ}$. As ações previstas no Art. $1^{\circ}$ serão desenvolvidas pelas Secretarias de Educação dos Estados e Municípios em consonância com as Secretarias Nacionais de Educação do Ministério da Educação (Brasil, 1991)

10 Os nomes passam a mudar por volta de 2008, quando foi iniciado o processo de estadualização. Os das duas primeiras instituições são referentes a importantes lideranças do período da retomada territorial, ao passo que os nomes que as escolas tinham antes da estadualização são de pessoas que meus interlocutores informaram não reconhecer. Sabemos, no entanto, que Marechal Rondon foi o presidente do primeiro órgão indigenista do Brasil.

11 Em uma mesma turma encontram-se alunos de diferentes séries, de modo que o professor, ao mesmo tempo, dá aula para algumas turmas em uma mesma sala de aula.

12 Não é possível ter um valor exato desses números, pois mudam semestralmente, devido ao alto índice de abandono no período da colheita e devido ao fato de que alguns contratos dos professores não duram mais do que um semestre. Tal assunto será detalhado adiante. 
Assim, é obrigação dos municípios e estados desenvolver e garantir os respectivos direitos a uma educação diferenciada que valorize os saberes e interesses da própria comunidade indígena. Isso não foi observado, contudo, no Município de Banzaê. Paula, ex-professora e atual liderança de uma das escolas, contou-me, por exemplo, que para os indígenas mudarem algo em seus colégios era necessária uma autorização da Prefeitura ${ }^{13}$, anulando o direito de autonomia administrativa sobre a escola. Além disso, existiria uma "espécie de má vontade" - expressão utilizada pelos próprios Kiriri para se referirem à falta de ajuda dos funcionários públicos - já que as pessoas que trabalhavam na Prefeitura, em geral, eram as mesmas que os discriminavam, fosse devido a preconceito, ou ao fato de acreditarem ter sido injusta a homologação do território indígena, considerando a luta dos Kiriri ilegítima. Segundo a diretora de uma das escolas, Jozilene, outro problema era que todas as funções tinham o mesmo regime de contrato, chamado Prestação de Serviço Temporário (PST). Os servidores trabalhavam ao longo do ano sem ter direito nem ao pagamento nas férias, nem ao décimo terceiro, além de não terem garantia de continuidade na carreira.

Percebemos aqui algo que Tassinari (2000) nos mostra. A autora demarca que as escolas indígenas são espaços de fronteira. Ela utiliza esse conceito a partir de Barth (1976), mostrando que a escola é um lugar interétnico, no qual uma etnia indígena internaliza em sua comunidade uma instituição estatal e, por isso, deve sempre estar em relação com o Estado, através dos respectivos órgãos responsáveis por esse lugar. Tassinari também elenca dois aspectos que surgem a partir dessa situação: as "relações interétnicas estáveis", que é quando podemos perceber que alguns elementos são promovidos de maneira mais harmoniosa sem conflitos e, em oposição a isso, as "zonas interditadas", constituídas por disputas e negociações relacionadas à garantia dos direitos indígenas.

Havia, pois, no cenário acompanhado interesses indígenas garantidos, como acesso à educação; porém, como já demonstrado, existia também um conjunto de problemas que inviabilizavam uma educação efetivamente diferenciada. Diante desse impasse, ao final dos anos 2000, os Kiriri vivenciaram o processo de estadualização dos estabelecimentos de ensino, o qual foi realizado de maneiras e períodos diferentes em cada colégio, até ser completado em meados da década de 2010. Ao cabo, puderam ter escolas com uma série de aspectos diferenciados, como um calendário específico, prevendo algumas aulas do ano letivo nos rituais ou nas matas do seu território, além de cardápio da merenda composto por comidas típicas dos Kiriri, autonomia nos processos administrativos e oferta de disciplinas específicas. Desse modo, ampliavam a possibilidade de uma maior convergência de interesses entre comunidade indígena e Secretaria de Educação.

O desenvolvimento de um conhecimento conteudista e didático que dê conta dessa demanda por uma educação diferenciada também passou, em consequência, a ser objeto da formação do corpo docente. Os(as) professores(as) participam de um programa nacional chamado Ação Saberes Indígenas, o qual é localmente desenvolvido pela Universidade Estadual da Bahia, através do grupo Opará, em parceria com a Secretária Estadual de Educação da Bahia. Tal programa tem como objetivos: promover uma formação continuada para os docentes indígenas; oferecer recursos didáticos e pedagógicos que serão desenvolvidos por cada comunidade de acordo com seus interesses; oferecer subsídios para 
desenvolvimento de um currículo diferenciado e para a definição de metodologias que atendam as demandas da comunidade; fomentar a pesquisa; elaborar materiais didáticos e paradidáticos. De acordo com meus interlocutores, esse programa tem sido muito importante para o ensino da cultura kiriti nas escolas. Voltarei a este ponto adiante.

Interessa-nos, nesse artigo, refletir especialmente sobre a relação dos kiriri com o direito a disciplinas específicas, como as de Cultura e Identidade e Língua Indígena. Na primeira, os indígenas estudam os aspectos relevantes para a comunidade, como os rituais, história do povo, suas lutas, direitos e tradições; na segunda, o foco é entender seu próprio idioma. Vale destacar que as demais disciplinas, equivalentes às ministradas em outras escolas públicas brasileiras, também contemplam, indiretamente, o direito à educação diferenciada, já que existe uma cobrança, por parte da comunidade, de que os professores associem os conteúdos curriculares nacionais com aspectos da sua aldeia, tais como: ensinar matemática relacionada às atividades da roça; correlacionar a história do Brasil com a da colonização indígena; explicar português a partir do português Kiriri que, como aponta Souza (2011), tem suas especificidades regionais e temporais.

Pude acompanhar aulas de Cultura e Identidade ministrada pela professora Jozineide, do Colégio Estadual Florentino Domingues de Andrade, em abril de 2019. Através desses momentos e de conversas informais com a docente, percebi que sua turma desenvolvia trabalhos escolares relativos à forma como os mais velhos da sua aldeia viviam, antes da retomada do território. Em conversas com Dernival, professor do Colégio Estadual Kiriri Índio Feliz, também pude notar que ele ensinava aspectos sobre o território, fazia aulas de campo com a turma, mostrando as serras e também solicitava trabalhos envolvendo realização de entrevistas com os pais, sobre práticas antigas dos Kiriri. Em diálogo com Gustavo, docente do Colégio Estadual José Zacarias, ele me contou, por sua vez, que abordava em suas disciplinas a luta dos kiriri pelos seus direitos, explicando para seus alunos como era desenvolvida a relação com diferentes secretarias do Estado da Bahia. Ou seja: nas três escolas essa matéria tinha como principais conteúdos as práticas tradicionais e ritualísticas, a história da luta pelos seus direitos étnicos e o conhecimento do território Kiriri.

$\mathrm{Na}$ disciplina de Língua Indígena, ministrada por Ivanildes, Dernival, Gustavo e Arivaldo, ensina-se a língua dos seus antepassados. $\mathrm{Na}$ aula da professora Ivanildes, da Escola Estadual Indígena Florentino Domingues de Andrade, vi que ela também ensinava conteúdos relacionados a outras línguas indígenas. Em conversas com os(as) docentes percebi que o conteúdo fica muito centrado em um léxico que não dá conta de preencher toda a carga horária, por isso acabam também ensinando assuntos que fazem parte do programa da disciplina Cultura e Identidade. É importante dizer que tudo que eles pensam sobre sua língua e ensinam está diretamente relacionado com os conhecimentos dos mais velhos e dos saberes rituais, como abordarei a seguir.

\section{Língua, tradição oral e escola}

A fala dos idosos é sempre tratada pelos Kiriri de maneira mais respeitosa. Através deles, sustenta-se e promove-se a tradição oral daquela comunidade e a memória desse povo. Dentre as pessoas mais 
antigas dessa etnia, alguns poucos dizem saber algumas palavras e seus significados. Por isso, muitos vocábulos que compõem seu léxico fazem parte das palavras que os mais velhos afirmam ser da sua própria língua. $\mathrm{Na}$ escola Kiriri, os saberes mais importantes são aqueles transmitidos no cotidiano; são alvo de tradução em conteúdo que assume um formato pedagógico na medida em que são inseridos no espaço escolar. Assim, os conhecimentos dos mais velhos transformam-se em objeto da aula do professor de língua indígena.

A esse respeito, menciono duas estratégias didáticas observadas durante a pesquisa. Uma relaciona-se à organização de uma gincana, que levou os(as) estudantes a pesquisar como os mais velhos se divertiam, de modo a reproduzir suas brincadeiras. Outra, diz respeito às entrevistas: estudantes foram orientados(as) a pesquisar sobre como se vivia antigamente e quais eram os hábitos mais comuns na época. Como resultado da pesquisa, aprenderam com os mais velhos que os Kiriri faziam atividades na roça, em grupo, as quais eram acompanhadas de algumas músicas, o que não mais se realiza. No dia do índio, em 2019, a professora Ivanildes organizou uma peça com a turma, na qual as músicas aprendidas foram então apresentadas. Percebe-se, assim, um esforço coletivo em manter na escola conhecimentos oriundos dos antepassados, valorizando estes saberes, sobretudo os de ordem linguística.

Além do contato com os mais velhos, outro modo de aprender sua língua é através do ritual. No toré existem momentos em que os encantados ensinam algumas palavras e frases, as quais podem ser usadas em momentos rituais e em processos de cura, ou para se proteger de alguma situação anômala. Os encantados podem pedir algo, como folhas, falando as palavras dessas ervas em sua própria língua. Isso é um modo de aprender o nome de elementos rituais importantes. É interessante notar que sempre que perguntava se existia diferença entre as palavras que os mais velhos ensinam e as que os encantados falam, os kiriri me respondem que apenas o sotaque muda.

Também existem pessoas que tem o "dom" de aprender melhor a língua com esses seres. "Dom" é uma categoria nativa que indica que uma pessoa nasceu com maior facilidade ou inclinação para aprender ou fazer algo. As lideranças, por exemplo, nasceram com o dom de liderar; alguns professores de língua indígena tem “o dom” de aprender a língua Kiriri e, muitas vezes, são os que mais entendem quando os encantados falam algo no seu idioma. Entre as pessoas que tem o "dom", são comuns os relatos de sonhos com os encantados lhes ensinando palavras Kiriri. Os sonhos não são compreendidos como uma realidade à parte, mas, antes, como um canal de comunicação com esses seres.

José Hamilton, ex-professor de Língua Indígena, é uma dessas pessoas. Quando dava aula, ensinava cantos do toré na língua - algo que, como vimos, foi muito importante no período da retomada territorial. Segundo seu entendimento, os cantos na língua "fortalecem" o ritual. A noção de "fortalecimento" é muito importante no vocabulário Kiriri, pois significa a ampliação da possibilidade de ser orientado pelas suas entidades sagradas e expandir a conexão com elas, de modo a alcançar seus objetivos de maneira mais satisfatória, plena e rápida ${ }^{14}$. Isso acontece não só para se referir à língua, mas a outros elementos; por exemplo, nas escolas kiriri eles fazem atividades que chamam de "fortalecimento

14 Outro ritual importante é o da “concentração”, o qual é bem restrito, apenas poucas pessoas o fazem. Os participantes se reúnem nas serras, em um pequeno grupo e, durante a concentração, ficam sentados, ouvindo os sons ao redor, como o canto dos pássaros e o balançar das folhas; em um determinado momento começam a ouvir palavras e frases na sua língua e, a partir daí, aprendem mais sobre seu idioma. 
cultural", as quais são relacionadas a aprendizados sobre o território, ritual e tradições, ampliando os conhecimentos oriundos dos encantados e sobre sua cultura. "Fortalecer" faz referência, portanto, a essa ideia de ampliar as possibilidades da agência dos encantados, o que por sua vez incide sobre o modo pelo qual os kiriri lutam por seus direitos. Nesse processo de "fortalecimento", José Hamilton buscou aprender várias palavras com os encantados; também aproveitou para tirar algumas dúvidas, perguntando a tradução de certas palavras.

Desse modo, é possível perceber que existe um saber que se retroalimenta em diferentes níveis. Os Kiriri aprendem a língua com os mais velhos e com suas entidades sagradas, depois a ensinam nas escolas. Isso é feito para "fortalecer" sua cultura e seus rituais. "Fortalecendo" o toré, utilizando a língua, ampliam sua comunicação com os encantados, podendo dialogar mais e melhor com eles, os quais, por sua vez, vão lhes ensinar mais sobre seu idioma, tornando possível dar prosseguimento à tradução desse saber em conteúdo escolar e à utilização desse conhecimento para "fortalecer" a cultura e os rituais. A retroalimentação que acabo de resumir perpassa o aprendizado linguístico na escola, visando que futuras gerações continuem esse movimento.

Tais processos, por sua vez, são convertidos em conteúdo escolar. Uma das operações envolve condensar esses conhecimentos em listas de palavras, de modo a ensiná-las na disciplina Língua Indígena. Além disso, os(as) docentes Kiriri criam diversas estratégias para difundir esses saberes oriundos dos rituais: em todas as escolas observei, por exemplo, a programação de aulas nas serras, nas quais o aprendizado sobre o território é feito por meio de caminhadas na mata. Como já mencionado, o calendário escolar também possibilita que os(as) docentes indígenas assumam os procedimentos ritualísticos como foco de suas aulas. Não por acaso, quando os rituais ocorrem nos dias de semana, os(as) professores(as) falam, por exemplo, que "a aula deve ser no ritual” Além disso, há atividades voltadas à criação de músicas do toré. Há, portanto, um fluxo de conhecimento, uma circulação contínua entre escola e ritual, de tal modo que podemos observar práticas rituais serem traduzidas em conteúdos escolares, o que condiciona os ensinamentos da disciplina língua indígena.

\section{Elaboração de material didático e disputas intra-étnicas}

Se, por um lado, os conhecimentos dos mais velhos e dos encantados perpassam as dinâmicas de ensino-aprendizagem das três escolas Kiriri, por outro, em cada uma delas, há modos próprios de elaboração dos materiais usados para ensinar a língua. Isso acontece devido a disputas específicas, como tratarei a seguir.

No Colégio Estadual Índio Feliz, o professor das disciplinas Língua Indígena e Cultura e Identidade é Dernival. Ele tem bastante conhecimento sobre a língua Kiriri e pesquisa o assunto junto ao grupo de jovens da aldeia de Cajazeiras, que se reúne periodicamente para se aprofundar em estudos sobre sua cultura. Levando em conta as obras de Mamiani, para Dernival a língua dos seus antepas- 
sados é o Kipeá15. Na escola onde Dernival atua, contudo, não se incorpora toda a obra do Mamiani ao seu léxico, porque é questionado se, de fato, era assim que seus antepassados falavam. Sabemos que a obra de Mamiani buscava diminuir as diferenças dialetais entre as línguas para que fosse possível se comunicar com o maior número de etnias diferentes. É provável que o que está ali, de fato, não seja exatamente igual ao que os antepassados dos Kiriri falavam, mas certamente era algo que possibilitava a comunicação com os indígenas que viviam onde hoje é o atual território Kiriri.

Além disso, poucos indígenas conhecem as obras de Mamiani e, mesmo dentre quem a conhece, podem não a entender em boa parte, pois para uma ampla compreensão são necessários conhecimentos prévios de linguística. Nenhum Kiriri estudou ou sabe como começar a estudar linguística para se apropriar dos materiais já existentes sobre o idioma. Desse modo, conseguem apenas compreender algumas palavras e a sua tradução, de modo que não sabem como estudá-las ou tirar melhor proveito desse material.

Frente a estas dificuldades, uma metodologia específica para o aprendizado do idioma kiriri foi elaborado por Dernival e o grupo de jovens de Cajazeiras. Eles repararam que muitas palavras que estão nas obras de Mamiani se assemelham a palavras que conheceram através das pessoas mais velhas, principalmente com Zito, um dos mais idosos. Zito tem uma lista de palavras que foi feita pelo seu pai, que quando jovem escreveu as palavras que sua avó sabia. As palavras de Zito e algumas outras que Dernival havia coletado com outros mais velhos foram a base para a criação de um livro chamado Kiriri-Kipeá, no qual ao final consta o primeiro dicionário da sua língua, publicado com recursos provenientes da participação de um edital.

No Colégio Estadual Indígena Florentino Domingues de Andrade, os professores João e Ivanildes usam esse mesmo livro. Porém, percebi que Ivanildes ensina também alguns conteúdos básicos da linguística, tais como: tronco linguístico; família linguística; variação dialetal; preconceito linguístico. Pude assistir a uma de suas aulas, na qual ela escreveu um pequeno texto na lousa sobre o assunto, junto de algumas questões, e depois discutiu o tema com os alunos. João também usa esse material, mas o complementa com ensino sobre as obras do Mamiani, localizando algumas palavras que acha que podem ser efetivamente da língua kiriri. Além disso, usa algumas palavras que aprendeu com José Hamilton, ex-professor de língua indígena do Colégio Estadual Indígena José Zacarias.

José Hamilton é umas das pessoas que mais conhece o idioma Kiriri. Boa parte do vocabulário foi aprendido com os mais velhos, principalmente com Gino, Bonifácio e Jô. Seus sucessores na escola, os professores Gustavo e Arivaldo, me relataram usar as palavras que aprenderam com José Hamilton. Algumas dessas palavras eram diferentes das que foram registradas por Dernival, porque os levantamentos foram feitos com idosos diferentes, possuidores de distintos conhecimentos da língua. Ao fazer um estudo minucioso da sua língua, José reparou que existiam termos que se assemelhavam às palavras compiladas por Maminani enquanto outras se diferenciavam, por isso não tem clareza se as obras desse

15 Rodrigues (2018) levanta a hipótese de que existe o tronco linguístico macro-jê e, assim sendo, a família linguística Kariri pertenceria a ele a língua e seria formada por quatro línguas: o Sapuya e Kamuru, falados na região de Pedra Branca, próximo da atual cidade de Cachoeira; Kipeá, falada no sertão nordestino, principalmente pelos Kiriri; o Dzubukuá falada na metade ocidental do submédio do rio São Francisco (Dantas et al, 1992). 
padre são, de fato, sobre a língua dos seus antepassados. Assim ele tem optado por ensinar o que aprendeu diretamente com os mais velhos, sobretudo, com Bonifácio, seu tio.

Essas diferenças na composição das estratégias didáticas para o ensino da língua kiriri e o manejo dos materiais didáticos ganham outra dimensão quando as relacionamos com os processos das divisões Kiriri. A este respeito, destaco que em 2019 existiam 8 caciques, cada qual relativo a um grupo de parentesco que lhes seguem: Hosano, Lázaro, Marcelo, Jailson, Agricio, Manoel, Roberto e João. Vejamos, muito sumariamente, como estas lideranças e grupos foram produzidos, bem como os efeitos destas divisões no acesso às escolas indígenas. É importante ressaltar que sei que o relato sobre estas cisões envolve a simplificação de um processo amplamente complexo e que durou décadas para se configurar; por ora, esta contextualização mínima já permite vislumbrar, no entanto, como as escolas ocupam lugar central na dinâmica das políticas indígenas.

É possível que a primeira divisão entre os kiriri tenha sido produzida pelo afastamento do grupo de Adrelina. Na época da retomada do território, Adrelina e sua família discordavam frequentemente de como o processo estava sendo conduzido e gradativamente foram afastando-se dos demais. Não fui informada sobre exatamente como ou em que época ela formou seu próprio grupo, apenas sei que ocorreu durante o processo de retomada territorial. Embora ela seja a maior liderança, o cacique é o seu filho, Roberto.

Outra divisão entre os kiriri ocorreu na década de 1980, também durante a retomada territorial. Segundo Nascimento (1994), Lázaro, o primeiro cacique, e algumas pessoas do seu grupo foram acusadas de se beneficiar das demarcações de maneira injusta. $\mathrm{O}$ ápice do conflito se deu quando o cacique propôs que existisse apenas um pajé, o qual é responsável por promover os torés e efetivar processos de cura, além de também exercer liderança e ter grande influência nas tomadas de decisões. Na época existiam três pajés e Lázaro queria que Zezão, quem mais lhe apoiava, fosse o único. Assim o cacique diminuiria o prestígio de outros pajés que lhe criticavam.

Os Kiriri não aceitaram isso e chegaram a um consenso de que os encantados deveriam indicar o novo pajé. O escolhido foi Adonias, quem mais sabia promover os processos de cura. Adonias e Lázaro tinham, no entanto, muitas desavenças e quando o primeiro passou a realizar os torés, Lázaro e seus aliados deixaram de participar dos rituais. A partir disso formou-se um novo grupo, tendo como cacique Manoel. Os grupos dividiram-se em termos territoriais: o grupo de Lázaro foi denominado Kiriri Mirandela, pois a maioria das pessoas era dessa aldeia ou de aldeias próximas; do outro lado, formou-se o grupo dos Kiriri Canta Galo, assim denominados por concentrarem-se mais nessa aldeia ou aldeias próximas.

$\mathrm{Na}$ época, nenhum dos grupos transitava pelo território onde estava o rival (diferentemente de como fazem hoje em dia). Em função disso, não frequentavam as escolas do grupo opositor, seja como aluno, professor ou funcionário. Por isso, o colégio hoje conhecido como José Zacarias era o frequentado pelos Kiriri Mirandela e as escolas hoje conhecidas como Índio Feliz e Florentino Domingues de Andrade, bem como seus anexos, ficaram sendo frequentados pelos Kiriri Canta Galo.

As divisões posteriores aconteceram entre os anos de 2008 e 2013. Meus interlocutores não souberem me informar o ano exato de cada processo que resultou em novas divisões, tanto nos Kiriri 
Mirandela, quanto nos Kiriri Canta Galo. Entre os primeiros, Lázaro teve conflitos com Marcelo, vice cacique do seu grupo; frequentemente divergiam sobre as tomadas de decisões e, em uma determinada situação, um conflito gerou a divisão dos grupos. Assim, Marcelo se tornou cacique, criando seu próprio segmento com sua parentela e aliados.

Após alguns anos, Marcelo envolveu-se em conflitos com relação a divisão de roças dentro do seu grupo e João, junto com algumas pessoas, questionaram isso. Sentindo-se injustiçados saíram do grupo e formaram um novo, elegendo João como cacique. Hosano também teve desavenças com Marcelo e, devido às divergências, saiu do grupo, formando um novo. Os grupos de Lázaro, Marcelo, Hosano e João ainda hoje se intitulam como Kiriri Mirandela e os integrantes dos seus respectivos grupos só podem frequentar o Colégio Estadual Indígena José Zacarias e seus anexos.

Entre os Kiriri Canta Galo o processo de cisão foi ligeiramente diferente, envolvendo uma série de discussões e de acusações graves entre as lideranças, inclusive as de roubo. Como resultante destas querelas, parte do grupo de Manoel saiu e escolheu Agricio como cacique do novo grupo. Como haviam duas escolas grandes no seu território, os grupos as dividiram entre si, de modo que o grupo de Agricio ficou com o Colégio Florentino Domingues de Andrade e o de Manoel, com o Colégio Índio Feliz.

Passados alguns anos, sucessivas brigas produziram nova cisão, separando os grupos de Manoel e de Jailson. Quando isso ocorreu, Jailson não conseguiu, contudo, se estabelecer enquanto liderança de nenhum colégio, por isso integrantes de seu grupo não podem ser funcionários dessas instituições. Estudantes oriundos de seu grupo, porém, frequentam as duas escolas dos Kiriri Canta Galo. Assim, os grupos que estão na aldeia de Mirandela frequentam o Colégio Estadual Indígena José Zacarias. O grupo do cacique Manoel frequenta Colégio Estadual Indígena Índio Feliz e o do cacique Agricio frequenta o Colégio Estadual Indígena Florentino Domingues de Andrade.

José Hamilton (do grupo de Lázaro) e Dernival (do grupo de Manoel) são, portanto, de grupos diferentes e ensinam palavras de mais velhos diferentes, por isso as palavras ensinadas nas escolas Kiriri não são iguais. Dernival e José reconhecem, porém, que, apesar de palavras diferentes, elas são bastante semelhantes entre si, bem como seus significados o são. Aparentemente algumas delas soam como variações linguísticas. Por exemplo: os professores do grupo de José Hamilton, ensinam que pai é painhequé16 , pois um dos mais velhos ensinou assim; outros professores ensinam que pai é padzú, pois assim viram na obra de Mamiani. Algumas palavras são consenso entre eles, tais como bêbado (wodó) ou fumo (bozé).

Os docentes do Colégio Estadual Indígena Florentino Domingues de Andrade - do mesmo grupo de Dernival - depois da cisão, porém, seguiram o grupo que surgiu com o cacique Agricio e, por isso, passaram a usar o livro feito pelo grupo de jovens de Cajazeiras. Nessa escola, a professora Ivanildes ensina as palavras compiladas por Dernival. O professor João, por sua vez, me disse que aprendeu algumas palavras com José Hamilton, pois reconhece nele uma pessoa que pesquisou bastante sobre a língua; por isso, apesar das disputas políticas, João compreende ser importante valorizar seu conhecimento.

16 Todas as palavras escritas aqui estão de acordo como os Kiriri escrevem. 
No geral, nenhum professor ensina mais de trezentas palavras, nem sabe ensinar a formar frases e, quando formam, é sem preposições. O léxico que conhecem está mais referente a nome de animais, plantas, artesanatos típicos dos Kiriri, comidas, fenômenos da natureza e, em menor número, a alguns adjetivos e nomes de objetos. As palavras que os mais velhos guardaram na memória, não por coincidência, são elementos típicos de uma identidade linguística, repleta de aspectos importantes para essa cultura.

Cada professor ou equipe de professores compõe, assim, o seu próprio léxico. Devido às dissidências políticas, acabam por discordar uns dos outros com certa frequência. Esse processo político é marcado pela noção que têm sobre a língua, na qual cada grupo reivindica para si a forma "certa" de se expressar no seu idioma. O ditado popular "saber é poder" se faz presente, já que saber a língua constitui um projeto importante para essa comunidade; aqueles que mais sabem sobre ela são mais procurados, requisitados e ocupam um lugar importante dentro do seu respectivo grupo político. Alguns estão entre os professores mais bem vistos das suas escolas; em contrapartida, os(as) docentes que mais se destacam também despertam desconfiança nos demais que também estudam a língua. Por consequência, isso interfere diretamente na tentativa de estruturar uma linguagem que possa ser falada por todos e que sirva como veículo de comunicação com seus ancestrais; cada qual faz isso separadamente, de maneira fragmentada, com distintas metodologias e pouco diálogo entre si.

Em conversa com Henio, sobrinho de José Hamilton, e ex-professor de língua indígena, percebi outros aspectos que levam os professores a ensinarem de diferentes formas. Esse docente contou que existem palavras que se escrevem com " $\mathrm{h}$ " e tem som de " $\mathrm{r}$ " ${ }^{17}$. Muitas pessoas não leem com o som do "r". Ele também contou que as palavras cagado (sambô) e jabuti (sambó) são escritas da mesma forma, porém devido ao acento as pessoas fazem confusão, sem chegar a um consenso sobre a grafia. Assim como a palavra brocoxo (avô) e inheque (vou, do verbo ir, no futuro) que também causam confusão, já que essas palavras tem som semelhante no português (sendo comum falar vô ao invés de avô).

Por conta desses fatos, existe uma contradição entre os ensinamentos dos diferentes professores. Percebemos isso no caso de livro Kiriri-Kipeá, já citado aqui. Ele é utilizado por diferentes docentes, em distintas séries e escolas, de modo que frequentemente um aluno estuda esse livro tanto na disciplina Língua Indígena quanto na de Cultura e Identidade, em várias circunstâncias diferentes. Não há uma forma consensual de usar esse material. Em conversa com os estudantes dos diferentes colégios, eles me relataram que o ensino da língua Kiriri é repetitivo e que não aborda diferentes aspectos, deixando neles a sensação de estudarem os mesmos conteúdos de maneira superficial, quando gostariam de realizar um estudo mais profundo e diversificado.

Além disso, o uso desse livro didático é cercado por polêmicas, pois sua produção não envolveu toda a comunidade, mas apenas o grupo de jovens de Cajazeiras. Algumas críticas relacionam-se, pois, há oposição a alguns membros do grupo produtor do livro; por questões políticas, portanto, esse livro passou a ser visto com certa desconfiança. Também são feitas outras acusações, como a de que o livro foi feito "de acordo com palavras da internet" - muitas vezes o termo internet é usado em referência à obra de Mamiani que, de fato, encontra-se disponível online -, ao invés de procurarem os mais velhos,

17 Em uma descrição fonética esse som seria equivalente aos tipos de "r" fricativo glotal vozeado e/ou fricativo glotal desvozeado 
ou de não procuraram os mais velhos de outros grupos políticos, como os da aldeia de Mirandela, mas apenas aqueles de quem eram mais próximos. A despeito dessas acusações, já mostramos aqui a influência dos mais velhos na construção nesse material. Assim, o único material didático que existe sobre o Kipeá acaba sendo perpassado por controvérsias.

Nesse ponto, vemos novamente o emergir de zonas interditadas, problematizadas por Tassinari (2000). Ao questionar os interlocutores sobre a inexistência de mais materiais sobre a língua kiriri, eles relataram que há muita dificuldade para a produção de materiais didáticos específicos. Às vezes, até conseguem elaborar algo junto ao programa Ação Saberes Indígenas, porém, por falta de verbas, o recurso didático acaba não sendo impresso ou não é possível concluir a proposta. Este foi o caso de dois materiais específicos - a saber: Nosso povo: leitura Kiriri, produzido em 2005, e Ler e escrever alfabetização nas escolas Kiriri e Kaimbé, de 2007, ambos feitos em parceria com o referido programa - que foram distribuídos uma única vez, de modo que só quem estava na escola naquela ocasião possuísse os livros.

Na minha última ida a campo, em 2019, soube que em Mirandela professores estavam produzindo seu próprio material sobre a língua kiriri. Buscavam organizar um dicionário, baseado nos saberes dos mais velhos dos grupos que frequentam a escola dessa aldeia. $\mathrm{O}$ material desenvolvido em parceria com o programa Ação Saberes Indígenas, intitulado Lingua indígena e o fortalecimento da identidade do povo Kiriri, porém ainda não foi publicado. Ou seja: embora esteja explícito na legislação acerca da educação diferenciada o direito ao material didático específico, notamos que a falta de verba inviabiliza sua produção, distribuição e manejo, prejudicando a promoção dos conteúdos oriundos dos saberes da própria comunidade indígena a qual se destina.

Apesar de todos os problemas descritos, os kiriri pesquisados concordam que a disciplina Língua Indígena assume lugar central na sua política identitária. Por conta dela, os indígenas veem a escola como o veículo da realização do projeto de voltar a falar a língua dos seus antepassados. Com essa disciplina, espera-se que os(as) professores(as) estudem sua língua e a ensinem para os(as) alunos(as), viabilizando a retomada linguística de modo mais amplo. Esse é um dos objetivos mais importantes dos Kiriri atualmente.

Existem dificuldades e limitações nesse processo, mas também existe muito desejo para que voltem a falar seu idioma. Neste sentido, vale destacar, por um lado, a relevância desses docentes para essa comunidade, por meio dos quais busca-se conferir à escola o estatuto de uma instituição efetivamente diferenciada, na qual são ensinados aspectos relevantes da cultura kiriri. Por outro, cabe reiterar a centralidade dos colégios nos processos que envolvem a construção da sua identidade, tornando-a o motor que promove o projeto de voltar a falar na língua.

Buscando solucionar problemas e elaborar estratégias didáticas para ensinar esses assuntos, os(as) professores(as) promovem suas aulas a partir do léxico que sabem. Dentre as metodologias relatadas por diferentes professores para ensinar essa disciplina, pude perceber que, em geral, há o ensinamento de algumas orações que estão no catecismo de Mamiani, orações as quais também constam no livro Kiriri-Kipeá. Em todas as escolas, acompanhei aulas nas quais se ensinavam orações inscritas no cate- 
cismo, tais como pai-nosso, Ave Maria, o sinal da santa cruz e a oração do credo. Também percebi a escrita na lousa das palavras que conhecem, seguidas de sua tradução.

A partir daí, cada professor tem seu método avaliativo para observar o processo de aprendizado dos estudantes. Dernival, por exemplo, desenvolvia junto a seus alunos trabalhos nos quais cada letra do alfabeto era associada a uma palavra na língua kiriri. Ele também pedia aos estudantes para fazerem trabalhos com uma palavra na língua Kiriri e um desenho a ela correspondente. Além disso, solicitava a elaboração de textos, nos quais, no meio de algumas frases, colocassem palavras no idioma indígena. João Eudes, por sua vez, além de usar slides para mostrar as palavras que conhecem, contou que gostava de usar métodos lúdicos, como a elaboração de jogos da memória com palavras na língua kiriri. Chegou também a ajudar os estudantes a fazerem uma peça de teatro na qual eles falavam palavras em kipeá. José Hamilton, em contrapartida, mostrou seu caderno, no qual fazia muitos desenhos e escrevia o nome de cada um desses desenhos na sua língua (por exemplo: a figura de um pote e, abaixo dele, o nome do objeto em kiriri). O que mais chamou atenção foi o desenho de um corpo humano e, próximo a cada parte, ele puxou uma seta, indicando os respectivos nomes na língua kiriri.

Percebemos, por meio destes exemplos, que existem relações interétnicas estáveis, no sentido que nos aponta Tassinari (2000), pois há o desejo desse grupo que existam disciplinas específicas, nas quais possam ensinar sobre sua cultura - sendo este direito garantido pelo Estado. Ao mesmo tempo, existem zonas interditadas, as quais podem ser observadas através da escassez de material didático específico. Com a possibilidade de se conectar mais com os encantados através do domínio da língua, construído com o conhecimento dos mais velhos e com a sistematização do ensino do seu idioma na escola, vemos avançar os seus conhecimentos linguísticos. Os Kiriri sabem mais do seu idioma que no período da retomada territorial; além disso, possuem espaços escolares para transmitir esse saber para as próximas gerações. Porém, devido ao seu pouco conhecimento acerca do léxico, às constantes disputas e à falta de verba para elaboração de mais materiais didáticos, tal saber não tem um alcance ainda maior.

\section{Considerações finais}

Procurei demonstrar como a perda linguística foi, de fato, a consequência do processo colonial. Vimos como foram implementadas políticas, através da educação escolar, no século XVII e XVIII, de tal modo que no século XX os kiriri já não sabiam mais se comunicar no seu próprio idioma, além de terem se tornado o segmento mais pobre e discriminado da região.

Para se opor a essa condição, os Kiriri precisaram rearticular um conjunto de saberes e práticas, demarcando sua identidade indígena que, até então, era fortemente negada. Foi necessário demonstrar através dos seus marcadores diacríticos que eram indígenas, detentores de direitos, sobretudo, do direito a um território. Neste contexto, a escola indígena e a língua passaram a ser valorizados: a escola podia lhes auxiliar alfabetizando-os nas letras e números, conhecimento imprescindível para não serem enganados; a língua, por sua vez, ampliava a comunicação com seus ancestrais, intensificando a agência destes e adensando o processo de retomada territorial. 
"Fortalecer" sua língua, revitalizando-a, é principalmente se opor a um projeto colonizador e opressor, revertendo e resistindo a processos históricos de violência. É reaver um patrimônio que foi parcialmente perdido devido a violências sofridas, mas que pode ser revivido mediante seus esforços. Falar na sua própria língua foi sendo assumida, assim, como uma expressão do que é ser Kiriri. Uma expressão da sua luta, do seu poder de articulação interna e, principalmente, da sua capacidade de realizar um projeto compartilhado por toda uma etnia.

Por isso, os Kiriri se esforçaram para que a educação diferenciada fosse um modo de efetivar a transmissão dos conhecimentos linguísticos. Através dos conhecimentos dos mais velhos e dos saberes oriundos dos rituais, os kiriri criam métodos próprios, transformando saberes tradicionais em conteúdos escolares por meio dos quais transmitem seu conhecimento, sobretudo, linguístico, para as gerações futuras. Através dessas instituições escolares, constrói-se sua identidade na relação com a língua.

Vanessa Coelho Moraes é Doutoranda de antropologia pela Universidade Federal da Babia (UFBA) e Mestranda de planejamento territorial pela Universidade Estadual de Feira de Santana (UEFS). A pesquisa desse artigo foi financiada pela Fundação de Amparo à Pesquisa do Estado da Bahia.

\section{REFERÊNCIAS}

Arruti, J. M. (1995). Morte e vida no Nordeste indígena: a emergência étnica como fenômeno histórico regional. Estudos Históricos, 8(15), 57-94. Disponível em https://bibliotecadigital.fgv.br/ojs/ index.php/reh/article/view/1995

Bandeira, M. de L. (1972). Os Kariris de Mirandela: Um grupo indígena integrado. Salvador: EDUFBA.

Barth, F. (1976). Los grupos étnicos e sus fronteras: la organización social de las diferencias culturales. México: Fondo de Cultura Económica.

Bartolomé, M. (2006). As etnogêneses: velhos atores e novos papéis no cenário cultural e político. Mana, 12(1), 39-68. https://doi.org/10.1590/S0104-93132006000100002

Brasil. (1991). Conselho Nacional de Educação. Decreto n 26. Diário Oficial da União.

Brasil. (1996). Conselho Nacional de Educação. Resolução nº 3. Diário Oficial da União. Brasília, 03 de outubro.

Brasil. (1999). Conselho Nacional de Educação. Parecer nº 14. Diário Oficial da União. 
Brasileiro, S. (1996). A organização política e o processo faccional no povo indígena Kiriri (Dissertação de Mestrado). Universidade Federal da Bahia, Salvador.

Chates, T. (2012). A domesticação da escola realizada por indígenas: uma etnografia histórica sobre a educação e a escola Kiriri (Dissertação de Mestrado). Universidade Federal da Bahia, Salvador.

Coelho, M. (1999). A civilização da Amazônia- Alexandre Rodrigues Ferreira e o Diretório dos Índios: a educação indígena e luso-brasileira, pela ótica do trabalho. Revista de História Regional, 5(2), $150-175$

Côrtes, C. N. (1996). A Educação écomo o Vento. Os Kiriri por Uma Educação Pluricultural (Dissertação de Mestrado). Universidade Federal da Bahia, Salvador.

Costa, F. (2013). Revitalização e ensino de língua: interação entre sociedade e gramática (Tese de Doutorado), Universidade Estadual de São Paulo, Araraquara.

Dantas, B. G., Sampaio, J., \& Carvalho, R. (1992). Os povos indígenas no Nordeste brasileiro: um esboço histórico. In: M. Carneiro da Cunha (org.). História dos povos indígenas (pp 430-456). São Paulo: Companhia das Letras.

Franchetto, B. (2020). Linguas indígenas ameaçadas: pesquisa e teorias linguisticas para revitalização. Disponível em: <http://nupeli-gela.weebly.com/revitalizaccedilatildeo.html> Acesso em 30 de abril de 2020

Giménez, G. (2007). Estudios sobre la cultura y las identidades sociales. México: Eco Cult.

Hanks, W. (2008). Lingua como prática social: das relações entre língua, cultura e sociedade a partir de Bourdieu e Bakhtin. São Paulo: Cortez.

Ingold, T. (2015) Antropologia não é etnografia. In: Estar vivo: ensaios sobre movimento, conhecimento e descrição (pp 327-348). São Paulo: Vozes.

Kiriri, D. et al. (2003). Índios na visão dos indios. Banzaê: FAZCULTURA.

Leite, S. (1945). História da Companhia de Jesus no Brasil. Rio de Janeiro: INL.

Mamiani, L. V. (1698). Catecismo da Doutrina Christãa na Lingua Brasilica da Nação Kiriri. Rio de Janeiro: Biblioteca Nacional.

Mamiani, L. V. (1699). Arte de Grammatica da Lingua Brasilica da naçam Kiriri. Rio de Janeiro: Biblioteca Nacional.

Moraes, V. (2018). A construção da escola indígena Kiriri (Monografia de Bacharelado). Universidade Federal da Bahia, Salvador. 
Moraes, V. (2020). O que devemos aprender com a ciência do indio? análise das contribuiçôes educacionais, epistemológicas e linguísticas dos saberes Kiriri (Dissertação de Mestrado). Universidade Federal da Bahia, Salvador.

Nascimento, M. T. de S. (1994). O tronco da jurema: ritual e etnicidade entre os povos indígenas do nordeste - o caso Kiriri (Dissertação de Mestrado). Universidade Federal da Bahia, Salvador.

Pompa, M. C. (2001). Religião como tradução: missionários, tupi e "tapuia” no Brasil Colonial (Tese de Doutorado). Instituto de Filosofia e Ciências Humanas, Universidade Estadual de Campinas, Campinas.

Reesink, E. (1983). Índio ou caboclo: notas sobre a identidade étnica dos índios do nordeste. Revista Universitas, 32(2), 121-138. https://periodicos.ufba.br/index.php/universitas/article/view/1028

Rodrigues, A. (2018). O artigo definido e os numerais na lingua Kirirí: Vocabulário na língua português-kiriri e kiriri-português. Revista Brasileira de Linguistica Antropológica, 4(2), 169-235. https:// doi.org/10.26512/rbla.v4i2.20679

Souza, H. (2011). Português Kiriri (Tese de Doutorado). Instituto de Letras, Universidade Federal da Bahia, Salvador.

Tassinari, A. (2000). Escola indígena: novos horizontes teóricos, novas fronteiras da educação. In: A. Silva, \& M. Ferreira (orgs.). Antropologia, história e educação: a questão indígena e a escola (pp 57-72). São Paulo: Global.

Vander Velden F. (2003). Combates singulares,historias singulares : sobre a participação indígena no movimento de canudos. Tellus, 3(4), 57-73. https://doi.org/10.20435/tellus.v0i4.64 


\section{A IMPORTÂNCIA DA ESCOLA NO PROCESSO DE AFIRMAÇÃo DA IDENTIDADE LINGUÍSTICA KIRIRI}

Resumo: Os Kiriri são do contexto etnológico do Nordeste, vivem no município de Banzaê-BA, e possuem um território demarcado de 12.320 hectares. Após passarem por um longo processo que culminou no fato de não saberem mais falar sua língua, apenas algumas palavras, iniciam um processo de afirmação identitária e de retomada territorial que envolveu sua língua e rituais. A ampliação dos seus conhecimentos linguísticos, seja por meio do registro do que os idosos sabem, seja do que aprendem sobre seu idioma no toré, efetiva a relação com seus antepassados e constitui os Kiriri no presente. Com base na pesquisa etnográfica realizada junto aos Kiriri em 2019, destaco como as escolas assumem lugar central na definição dos termos da política étnica, tornando-as espaços centrais na afirmação identitária e na produção de saberes específicos. Neste artigo, as disputas e os desafios em torno do ensino das disciplinas Língua Indígena e Cultura e Identidade são o foco da análise.

Palavra-chave: educação diferenciada; Kiriri; língua indígena; escola indígena; revitalização linguística.

\section{THE IMPORTANCE OF THE SCHOOL IN THE PROCESS OF AFFIRMING THE KIRI- RI LINGUISTIC IDENTITY.}

Abstract: The Kiriri is from the ethnological context of the Northeast, lives in the municipality of Banzaê-BA, and has a demarcated territory of 12,320 hectares. After going through a long process that culminated in the fact that they no longer know how to speak their language, just a few words. They begin a process of identity affirmation and territorial recovery that involved their language and rituals. The expansion of their linguistic knowledge is through recording what the elderly know, or what they learn about their language in the Toré, effective relationship with their ancestors and constitutes the Kiriri in the present. Based on the ethnographic research carried out with the Kiriri in 2019, I highlight how schools play a central role in defining the terms of ethnic policy, making them central spaces in the affirmation of identity and the production of specific knowledge. In this article, the disputes and challenges surrounding the teaching of Indigenous Language and Culture and Identity disciplines are the focus of the analysis.

Keywords: Differentiated Education; Kiriri; Indigenous Language; Indigenous School; Linguistic Revitalization.

RECEBIDO: $30 / 04 / 2020$

ACEITO: $30 / 06 / 2021$ 